\title{
DECISION SUPPORT OF SPARE PARTS SUPPLY
}

\author{
Sebastian Kot ${ }^{1}$, Jerzy Lodziński ${ }^{2}$ \\ Institute of Logistics and International Management, Czestochowa University of Technology \\ Czestochowa, Poland \\ ${ }^{1}$ sebacat@zim.pcz.pl, ${ }^{2} j l o d z i n s k i @ w p . p l$
}

\begin{abstract}
Decisions concerning the way of purchasing spare parts affect the level of the generated costs of collecting and maintaining stocks as well as the level of maintaining the continuity of production in enterprises. To learn about different situations of spare parts purchasing appearing in real economic conditions there has been conducted the simulation of different scenarios of spare parts purchase in connection with the selected factors. In this paper the case study for replacement parts used in a printing house was considered. As a result of the analysis, the best option to purchase replacement parts was indicated.
\end{abstract}

Keywords: inventory control, purchase costs

\section{Introduction}

The stock of spare parts for machinery and equipment, on account of a different character in comparison with other material stocks, involves a slightly different approach in terms of managing it [1]. This stock is not a constituent of a final product and the predictability of the demand for it is considerably limited. Apart from specifying the critical stock absolutely indispensable in a warehouse, it is also important to manage the purchase of the remaining spare parts in such a way that the continuity of production is guaranteed at the highest possible level $[2,3]$. The employees of the warehouse are provided with two options of purchasing spare parts which are not the critical stock:

- to purchase a given spare part before the demand for exchanging the item appears,

- to purchase a given spare part at the moment of the appearance of such a demand.

The first variant of decision-making concerns collecting and maintaining the stock in the warehouse in advance while limiting the length of machinery stoppages to the time essential for its repair and, at the same time, ensuring the required continuity of operational processes. Maintaining the stock in the long term will generate, however, additional costs connected with freezing the capital and the elements getting older which will negatively affect the economic situation of the enterprise.

The other variant will not increase the costs connected with the storage of the inventory since they will be supplied after the demand appears. However, in such 
a case the equipment stoppage will be extended which will considerably influence the continuity of the production processes.

It is difficult to indicate clearly which option of purchasing spare parts is more advantageous. Reduction in repairs that are not planned involves guaranteeing availability of parts at the highest level, thus their previous purchase and maintenance in the warehouse seems to be rational. On the other hand, the early purchase of stocks freezes cash, thus simultaneously generating costs of the lost opportunities.

\section{A one-time purchase or a multiple one?}

To analyze the possible costs borne to purchase and maintain spare parts, there has been taken into consideration a standard element characterized by the highest degree of predictability and regularity of collection from the warehouse per year. The main purpose is to lower the level of frozen capital on the basis of the changes in the number of supplies of a given item. The employees of the warehouse are to choose from the two possibilities of purchasing goods per year presented in Table 1: - purchasing the whole average annual demand in one supply,

- purchasing the required number of a given item in separate deliveries realized a few times a year.

These results may be generalized provided that the following conditions are satisfied:

- standard and non-repairable spare parts which may be the applied in a printing house are taken into consideration,

- these parts are the subject to the exchange in a printer at least twice a year,

- annual contract ni $=1,2, \ldots, \mathrm{i}$ - amounts to the number of contracts for a given item a year,

- minimum possible transport cost is the same for each delivery,

- the rate of annual cost of maintaining the stock of spare parts amounts to $W_{k u}=20 \%[4]$.

In Table 1, the purchase of a bearing for printer, the exchange of which takes place on average three times a year, was considered. The method of estimation of the individual data is as follows:

- the average number of the analyzed part collections to be counted as the arithmetic mean of the given item purchased in each year for a period of 3 years based on the formula [5]:

$$
Q d=\frac{1}{N} \sum_{i=1}^{n} q d_{i}
$$

where:

$Q d$ - the average annual volume of items ordered,

$q d_{i}$ - i-th number of the given part collections during the year for $i=1,2,3, \ldots, n$,

$N$ - number of years, in which the part collections were recorded; 
- the average purchase price is the arithmetic average of the unit price (prices are subject to change due to supplier changes, profit margins, etc.):

$$
P=\frac{\sum_{i=1}^{n} p_{i}}{\sum_{i=1}^{n} q d_{i}}
$$

where:

$P$ - the average unit price of the purchase,

$p_{i}$ - $i$-th gross unit price of the part for $I=1,2,3, \ldots, n$;

- the minimum delivery charge was determined based on the offers of the major courier companies operating in Poland assuming that the weight of the considered part does not exceed $10 \mathrm{~kg}$. The minimum delivery charge marked as $P s_{\min }$ for such part in Poland is now at least 22 zloty;

- Delivery volume in the $N$-th year is dependent on the average number of the given part collections, and this should be at least 1 :

$$
Q s_{1} \in\langle 1 ; \max Q d\rangle
$$

- the average value of the stock is the total purchase cost of the parts for a single or a combined unit delivery that contains the gross price of the parts and a delivery charge:

$$
V I=(P * Q S)+P s_{\text {min }}
$$

- the annual maintenance cost for a given number of parts in the warehouse was estimated as the product of the average unit price, the delivery volume and inventory maintenance indicator:

$$
H C=\left(P^{*} Q s_{1}\right)^{*} W_{k u}
$$

where:

$W_{k u}$ - inventory maintenance indicator in the tested case is $20 \%$;

- the total annual storage cost of the parts were expressed as the sum of the inventory value and the annual maintenance costs for the given item:

$$
T C=V I+H C
$$

Table 1

Creating costs of collecting and maintaining stocks with two options of purchasing

\begin{tabular}{|c|l|c|c|c|c|c|c|c|}
\hline \multicolumn{2}{|c|}{ Option of purchasing } & $\begin{array}{c}Q d \\
\text { (No) }\end{array}$ & $\begin{array}{c}P \\
\text { (zloty) }\end{array}$ & $\begin{array}{c}P S_{\min } \\
\text { (zloty) }\end{array}$ & $\begin{array}{c}Q s_{1} \\
\text { (No) }\end{array}$ & $\begin{array}{c}V I \\
\text { (zloty) }\end{array}$ & $\begin{array}{c}H C \\
\text { (zloty) }\end{array}$ & $\begin{array}{c}T C \\
\text { (zloty) }\end{array}$ \\
\hline I & Purchase in one delivery & 3 & 40 & 22 & 3 & 142 & 24 & 166 \\
\hline II & Purchase in a few deliveries & 3 & 40 & 22 & 1 & 66 & 0 & 198 \\
\hline
\end{tabular}


I. The first option of purchase concerns the realization of the whole annual contract once in one delivery. In the first case the cost of maintaining the stock amounts to 24 zloty, whereas the transport cost is borne only once.

II. The second option assumes that the contract is realized in three separate deliveries and each of the supplied parts is removed from the warehouse in the shortest possible time (up to 30 days), while not generating considerable costs of maintenance. The transport cost is borne three times which causes the costs related to satisfying the demand to be higher than in case of the first option of purchase.

While choosing one-time deliveries, due to the averaged value of the annual demand, there is a possibility that further deliveries will not be necessary on account of lack of the demand, which, with a one-time purchase, would make the stock of spare parts occupy the warehouse. It is also not possible to exclude the increased demand, exceeding the average annual level generating additional costs of another delivery in both cases. Changes in the level of fluctuation of spare parts result mainly from:

- changes in the level of production,

- conducted strategy of repairs,

- substituting parts with other replacements.

Summing up, in respect of the size of the frozen capital while assuming the same transport costs the most beneficial is the second option of purchase. However, while taking into consideration the total costs borne within the year of the purchase, transport and maintenance of goods, the most advantageous option is the aggregated purchase [6]. The way of selecting the purchase of parts ought to be determined by the way of the conducted strategy of repairs and maintenance. The schedule of the planned inspections and repairs may considerably limit the unpredictability of the demand, while at the same time allowing for the purchase of parts before the intended repair, which is equivalent to the second variant of decision-making.

\section{Simulation of unit prices of standard spare parts}

Standard spare parts are usually divided into two groups:

- the first one refers to standard parts which, in spite of low unit cost, are purchased individually,

- the second one refers to so called 'minor' parts, whose very low unit cost and short term viability cause them to be usually sold in multipacks or by weight.

Depending on the group a given part belongs to, it is necessary to take into consideration each single size of the delivery so that the transport costs will not exceed the value of a one-time contract. Presented below are two simulations of formation of the total costs of purchase and maintenance of spare parts from the two groups. 


\subsection{The simulation of the unit costs of the standard parts which are more expensive}

While assuming different distribution of transport costs depending on the size of a single contract $Q s_{i}$, there have been established such unit costs of an item $P_{b a l}$ (price of balance) which compensate the total costs of maintenance of parts for the first and the second option of purchase, providing the same minimum transport cost $P s_{\min }$. This time in Table 2 the purchase of the item has been analyzed whose annual demand amounts to maximum 5 items a year, when the unit price $P$ represented price equilibrium $P_{b a l}$, then the total inventory storage costs were the same for the first and second option of purchase, which can be written as:

$$
P \rightarrow P_{b a l} \Leftrightarrow S C_{I}=S C_{I I}
$$

Table 2

The level of the unit price compensating the total costs of different options to purchase

\begin{tabular}{|l|c|c|c|c|c|c|}
\hline $\begin{array}{c}\text { Option of } \\
\text { purchasing }\end{array}$ & $\begin{array}{c}P S_{\min } \\
\text { (zloty) }\end{array}$ & $\begin{array}{c}Q s_{i} \\
\text { (No) }\end{array}$ & $\begin{array}{c}P_{b a l} \\
\text { (zloty) }\end{array}$ & $\begin{array}{c}V I \\
\text { (zloty) }\end{array}$ & $\begin{array}{c}H C \\
\text { (zloty) }\end{array}$ & $\begin{array}{c}T C \\
\text { (zloty) }\end{array}$ \\
\hline Option 1 & 22 & 2 & 54 & 108 & 21,6 & 152 \\
\hline Option 2 & 22 & 1 & 54 & 54 & 0 & 152 \\
\hline Option 1 & 22 & 3 & 73 & 219 & 43,8 & 285 \\
\hline Option 2 & 22 & 1 & 73 & 73 & 0 & 285 \\
\hline Option 1 & 22 & 4 & 83 & 332 & 66,4 & 420 \\
\hline Option 2 & 22 & 1 & 83 & 83 & 0 & 420 \\
\hline Option 1 & 22 & 5 & 88 & 440 & 88 & 550 \\
\hline Option 2 & 22 & 1 & 88 & 88 & 0 & 550 \\
\hline
\end{tabular}

The total costs of the maintenance of goods for the contract realized in one delivery or the one realized with the help of a few deliveries will be in balance when:

- for the annual contract amounting to 2 units, a single unit price of the item equals 54 zloty,

- for the annual contract amounting to 3 units, a single unit price of the item equals 73 zloty,

- for the annual contract amounting to 4 units, a single unit price of the item equals 83 zloty,

- for the annual contract amounting to 5 units, a single unit price of the item equals 88 zloty.

The indicated prices of a given item, when the transport cost is known, allows us to make a choice between the two suggested options of purchase in a more rational and reasonable way. 
The correspondence of the formation of the unit price $P_{b a l}$, transport cost $P s$ and total cost of purchase $T C$ between the analyzed options of purchase is presented in Figure 1.

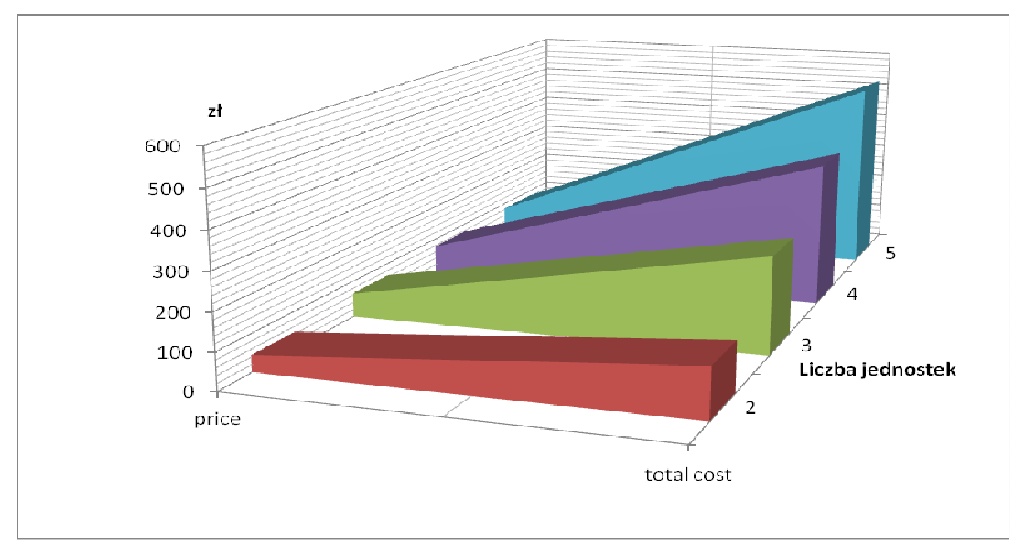

Fig. 1. The functional relationship between the unit price and the size of the annual contract for the cost-effective balance of the options of purchase I and II

Along with an increase in the unit price and the size of the contract, the total costs of purchasing goods go up. Each price increase by 1 zloty above the equilibrium point brings about an increase in the total cost of maintenance by 4 zloty for the option I and increase in the total costs of purchase by 3 zloty for the option II. The total costs of goods from one delivery will change faster than the costs of goods for a few deliveries.

To sum up, with the same transport costs, each fall in the level of the unit price of the item will cause an increase in the total holding costs of goods purchased in a few deliveries, each price increase of this item, in turn, will bring about an increase in the costs of maintenance of goods purchased in one delivery. This means that along with an increase in the unit price above the level which balances the total costs of maintenance, it will be more useful to realize the contract in separate deliveries, which is, by choosing the second option to purchase.

These principles may be applied to the standard spare parts whose unit costs stay at the price range similar to the one given as an example.

\subsection{The simulation of the unit costs of the standard parts which are cheaper (the minor ones)}

The identical simulation of costs has been conducted for the standard positions which are characterized by very low unit costs, therefore, they are usually purchased in multipacks or by weight. It has been assumed that along with increase in the unit price of goods, there is increase in profitability of maximizing the frequency of deliveries. Thus, the second option of purchasing has been analyzed for a different number of deliveries per year. Below, is an estimation the size of the contract 
$S_{i}(i=1,2,3, \ldots, n)$ for the item from this group of stocks for which the level of the total holding costs is balanced for the two options of purchase, when transport cost $P s_{\min }=$ const and suggested price $P_{s g}$ will be increase consecutively by one unit for each option (Tab. 3).

Table 3

Exemplary sizes of contracts providing cost-effective balance for minor parts with the given unit prices

\begin{tabular}{|c|c|c|c|c|c|c|c|}
\hline $\begin{array}{c}\text { Option of } \\
\text { purchase }\end{array}$ & $\begin{array}{c}P s_{\min } \\
\text { (zloty) }\end{array}$ & $\begin{array}{c}Q s_{i} \\
\text { (No) }\end{array}$ & $\begin{array}{c}S_{i} \\
\text { (times) }\end{array}$ & $\begin{array}{c}P_{s g} \\
\text { (zloty) }\end{array}$ & $\begin{array}{c}V I \\
\text { (zloty) }\end{array}$ & $\begin{array}{c}H C \\
\text { (zloty) }\end{array}$ & $\begin{array}{c}T C \\
\text { (zloty) }\end{array}$ \\
\hline 1 & 22 & 400 & 1 & 2 & 800 & 160 & 982 \\
\hline 2 & 22 & 470 & 2 & 2 & 940 & 0 & 984 \\
\hline 1 & 22 & 250 & 1 & 3 & 750 & 150 & 922 \\
\hline 2 & 22 & 95 & 3 & 3 & 855 & 0 & 921 \\
\hline 1 & 22 & 150 & 1 & 4 & 600 & 120 & 742 \\
\hline 2 & 22 & 41 & 4 & 4 & 656 & 0 & 744 \\
\hline 1 & 22 & 101 & 1 & 5 & 505 & 101 & 628 \\
\hline 2 & 22 & 21 & 5 & 5 & 525 & 0 & 635 \\
\hline
\end{tabular}

The total costs of maintenance of goods for the contract realized in a single delivery and a few deliveries will be similar when:

- for the goods of the unit price amounting to 2 zloty there will be a realization of one delivery of 400 units or two deliveries of 470 units,

- for the goods of the unit price amounting to 3 zloty there will be a realization of one delivery of minimum 250 units or three deliveries of 95 units,

- for the goods of the unit price amounting to 4 zloty there will be a realization of one delivery of minimum 150 units or four deliveries of 41 units,

- for the goods of the unit price amounting to 5 zloty there will be a realization of one delivery of minimum 101 units or five deliveries of 21 units.

Ordering goods at a price ranging from 1 zloty per unit to 5 zloty per unit in one delivery involves a higher level of contract than in the case of a few deliveries simultaneously. The lower the unit price of the goods is the bigger the contract must be so as to balance the increasing total costs of purchase. Along with an increase in the unit price, and while assuming the same transport costs irrespective of the size of a single delivery, there is observed the decline in the total costs borne for purchase and maintenance of the 'minor' spare parts a year.

\section{Conclusion}

Presented in this paper is the evaluation of profitability of the two options of purchase of the average annual contract of the items which are relatively regularly 
utilized, in the result of which it has been proved that in respect of the size of the frozen capital, while assuming identical transport costs, the most advantageous is the option 2 which refers to the realization of the average annual contract in a few deliveries.

Due to different distribution of the transport costs depending on the price of the standard parts there have been assessed such unit prices which would be guaranteed by the same total cost of purchase of parts for both options of purchase. In the case of 'more expensive' standard parts along with increase in the unit price above the level which balances the total costs of maintenance, it is more beneficial to realize the contract in single deliveries, which is, by selecting the second option of purchase. In the case of cheap standard parts - the lower the unit price of the goods is the bigger the contract realized in a single delivery must be so as to balance the increasing total costs of purchase. Therefore, it is more advantageous to purchase this type of parts by selecting the first option of purchasing parts. The final way of selecting a spare parts purchase ought to be determined by the kind of the conducted strategy of repair and maintenance.

\section{References}

[1] Dima I.C., Grzybowski A.Z., Grabara J.K., Statistical Modeling of ohe Mechanical Properties of the Heavy Steel Plates - Dealing with the conditioned data, Metalurgia International 2013, XVIII, 1.

[2] Grabara J., Dima I.C., Kot S., Kwiatkowska J., Case on in-house logistics modeling and simulation, Research Journal of Applied Sciences 2011, 6(7-12).

[3] Kot S., Grondys K., Sopa R., Theory of Inventory Management Based on Demand Forecasting, Polish Journal of Management Studies 2011, 3.

[4] Krzyżaniak S., Podstawy zarządzania zapasami w przykładach, Biblioteka Logistyka, Poznań 2002.

[5] Nowak E., Metody statystyczne w analizie działalności przedsiębiorstwa, PWE, Warszawa 2001.

[6] Kot S., Ślusarczyk B., Process simulation in supply chain using logware software, Annales Universitas Apulensis Series Oeconomica 2009, 211. 